Estudios Constitucionales, Año 17, No 1, 2019, pp. 443-458

ISSN 07180195

Centro de Estudios Constitucionales de Chile Universidad de Talca

"El derecho a contraer matrimonio de los extranjeros.

(Sentencia Corte Suprema, 18 de abril de 2018, rol No 6111-2018)"

Rodolfo Montecinos Ohlagaray

\title{
EL DERECHO A CONTRAER MATRIMONIO DE LOS EXTRANJEROS* (SENTENCIA CORTE SUPREMA, 18 DE ABRIL DE 2018, ROL No 6111-2018)
}

THE RIGHT TO CONTRACT MARRIAGE FOR FOREIGNERS (Supreme Court, APrIL 18 ${ }^{\mathrm{TH}}$, 2018, ROL No 6111-2018)

\author{
Rodolfo Montecinos OhlagaraY ${ }^{* *}$ \\ Universidad Mayor \\ rodolfojmontecinos@gmail.com
}

RESUMEN: El presente comentario de jurisprudencia analiza una sentencia de la Corte Suprema chilena que derogó tácitamente el artículo 76 del Decreto Ley No 1.094, de 1975, dado que, en su consideración, el contenido de la norma transgrede normas contenidas en la Constitución Política de la República, que tratan ciertos derechos que emanan de la naturaleza humana. Para la corte, el precepto impugnado perdió su vigencia; así, en virtud de sus potestades jurisdiccionales, estimó no aplicarlo para el caso particular.

Este fallo destaca una discusión relevante, ya que reconoce la atribución y ejercicio de derechos humanos de parte de nacionales y extranjeros, y en el caso de estos últimos debe distinguirse la posible situación migratoria que mantengan en el Estado chileno. El presente trabajo busca dilucidar la calidad jurídica de la persona extranjera que pretende el reconocimiento, en el ejercicio de ciertos derechos que le han sido concedidos por su naturaleza humana, por parte del Estado.

ABSTRACT: This work analyses a sentence of the Supreme Court of Chile that tacitly abolished the art. 74 of the D.L. No 1.094, 1975 provided that in his opinion, the content of the rule was not compatible to the Constitution, that treat some rights that have been conceived for his human nature. According to the Court, the pre-constitutional precept lost validity and, in consequence, in use of his jurisdictional authority, estimated not to apply in this particular case.

This case is important for a relevant discussion, because recognize the attribution and exercise of their human rights for nationals and foreign, in particular for this last according to its migratory situation that keep in the chilean State. This work is trying for establish the juridical status of the foreign person who pretends the gratitude, in the exercise of his rights which has been given by his human nature, in presence of the State.

\footnotetext{
* Trabajo recibido el 31 de octubre de 2018 y aprobado el 28 de noviembre de 2018.

** Abogado (Chile). Licenciado en Derecho de la Universidad Mayor (Chile). Pasante de la Organización Humanitaria No Gubernamental ADRA Slovensko (Eslovaquia). Expostulante de la Oficina Especializada en Derechos Humanos de la Corporación de Asistencia Judicial (Chile).
} 
PALABRAS CLAVE: Residencia legal, igualdad jurídica, Corte Suprema.

KEY WORDS: Legal residence, juridical equality, Supreme Court.

La Corte Suprema, con fecha 18 de abril de 2018, en votación dividida ${ }^{1}$, acogió una acción de protección y declaró arbitrario e ilegal el actuar discriminatorio del Servicio de Registro Civil e Identificación de impedir un matrimonio entre un chileno y una colombiana, por no tener esta residencia legal en Chile.

Según se da cuenta en el voto de mayoría, la normativa que establece esta exigencia es el artículo 76 del Decreto Ley No 1.094, de 1975, que, en la actualidad no está vigente, por ser contraria a normas posteriores de rango superior, reguladas en la Constitución Política de la República y tratados internacionales de derechos humanos ratificados por Chile y actualmente vigentes; en concreto, la igualdad ante la ley, la igual protección en el ejercicio de los derechos, y la protección a la vida privada y la familia. De igual manera, la corte razonó que se vulneraba el artículo 17.2 de la Convención Americana de Derechos Humanos, en cuanto al derecho a contraer matrimonio y fundar una familia que se reconoce a toda persona, incorporado en nuestro ordenamiento jurídico a través del artículo $5^{\circ}$, inciso $2^{\circ}$, de la Constitución Política de la República, al tratarse de un tratado internacional que versa sobre derechos esenciales que emanan de la naturaleza humana y estar ratificado por Chile y actualmente vigente.

El fallo es relevante por las siguientes consideraciones: a) el desarrollo del ejercicio de los derechos de la población extranjera que mantiene una situación migratoria irregular en el territorio nacional, en consideración al trato que debe brindarle el Estado en asuntos que emanan de su competencia, pudiendo preguntarse al respecto ¿cuál es la calidad jurídica del extranjero, tanto en situación migratoria regular e irregular, en cuanto al ejercicio de sus derechos humanos? ¿Son reconocidos y ejercidos de la misma forma que los nacionales ante los organismos del Estado?; b) los tribunales deben ejercer jurisdicción conforme al derecho aplicable y, para tal efecto, recurren a todo el sistema de fuentes del ordenamiento jurídico, internas e internacionales, dentro de las cuales está la Constitución y

${ }_{1}^{1}$ Los ministros señor Sergio Muñoz G. y señor Carlos Aránguiz Z., y el abogado integrante señor. Rafael Gómez B. estimaron confirmar el fallo de primera instancia, que acogió el recurso de protección. La ministra señora María Eugenia Sandoval G. y el ministro señor Arturo Prado P. rechazaron la sentencia de primera instancia. 
los tratados internacionales; c) la Corte Suprema estimó que, en la especie, cesó la vigencia del artículo 76 del Decreto Ley No 1.094, de 1975, y, por lo tanto, lo que declaró en su sentencia fue constatar la derogación tácita del precepto legal cuestionado, dado que su contenido era incompatible en su integridad con un conjunto de disposiciones posteriores previstas en la Constitución, en tratados internacionales que versan sobre derechos humanos, tales como la Convención Americana de Derechos Humanos, y la normativa actual vigente.

Esta sentencia generó controversia, puesto que la Corte Suprema, como tribunal ordinario, optó por no aplicar una norma previa por considerarla contraria a la Constitución, aun cuando el control de constitucionalidad de leyes, en virtud del principio de supremacía constitucional, lo ejerce el Tribunal Constitucional ${ }^{2}$, así como también existe una dualidad en cuanto a la interpretación y alcance de los derechos humanos que por una parte realizan los tribunales superiores de justicia, conociendo de la acción de protección, amparo, entre otros, y además el Tribunal Constitucional, como órgano que vela por que el ordenamiento jurídico en su conjunto sea dictado, formal y materialmente, conforme a la Constitución Política de la República.

En tal consideración, el propósito de este comentario de jurisprudencia es dilucidar la calidad jurídica que mantienen en el territorio de la República las personas que, al momento de ejercer los derechos, sean dichas personas nacionales o extranjeras, y en el caso de estas últimas atendiendo a la situación migratoria que estas mantienen en el Estado chileno. Conforme a la normativa legal y reglamentaria vigente, señalar de qué forma la disposición del artículo 76 del Decreto Ley No 1.094, de 1975 (Establece normas de extranjeros en Chile), resulta atentatoria a los derechos humanos y la relación que mantiene la situación migratoria de una persona extranjera con la capacidad que tiene para celebrar un contrato de matrimonio. Es menester señalar que, hasta esta sentencia, no existía uniformidad en la jurisprudencia en cuanto a determinar el reconocimiento en el ejercicio de derechos, invocados en el caso, entre nacionales y extranjeros a fin de determinar el cese de la vigencia de una normativa legal preconstitucional y el conflicto que genera con la Constitución Política de la República, por lo que se puede concluir que es un caso inédito ${ }^{3}$ de reconocimiento jurisdiccional al igualitario ejercicio de los derechos en Chile.

2 ROJAS (2017).

3 Junto a las sentencias de la Corte Suprema de fecha 30 de agosto de 2016 y 12 de julio de 2018, roles Nos. 35236-2016 y 12130-2018, respectivamente, casos de similares características de hecho, en que alguno de los intervinientes resultan ser extranjeros con situación migratoria irregular en nuestro país. 


\section{ANTECEDENTES DEL CASO}

Ladis Mondragón, colombiana, y Emilio Meneses, chileno, solicitaron hora para contraer un matrimonio en la oficina del Servicio de Registro Civil e Identificación de la comuna de Recoleta, lo cual fue otorgado por la funcionaria con el requisito de que, a la llegada del día de la celebración, la nacional colombiana presentara la documentación que acreditara su residencia legal en Chile, esto es, su cédula de identidad para extranjeros o la tarjeta de embarque otorgada por la Policía de Investigaciones en el control fronterizo. Dado que no poseía ninguno de estos documentos, al registrar esta un ingreso clandestino al país en el año 2014, por no tener a la fecha su situación migratoria regular, y registrar un decreto pendiente de expulsión de Chile, fue denegada la celebración del matrimonio, pese a que ambos cumplían los requisitos de la Ley de Matrimonio Civil, Ley No 19.947, de 2004: a) ser mayores de 18 años, b) no estar afectos a ningún tipo de impedimentos ni prohibiciones, y c) concurrir con dos testigos hábiles.

La decisión de impedir el matrimonio implicó para los recurrentes una afectación de sus derechos fundamentales; en específico, el que asegura a todas las personas la igualdad ante la ley y la protección a la vida privada y su familia. En efecto, se argumentó que el pasaporte de la señora Mondragón era un documento de identidad válido, idóneo y suficiente para acreditar la identidad de quien pretendía celebrar el mencionado contrato. Por otra parte, el funcionario vulneró la Ley Orgánica del Registro Civil en lo referido a sus obligaciones señaladas en el artículo 33 de la Ley No 19.477, de 1996, por cuanto esta norma y el Decreto No 673, de 2004, no han establecido el deber del oficial del Registro Civil de verificar que uno o ambos contrayentes estén en situación migratoria regular para los efectos de conceder o denegar la celebración de un contrato de matrimonio.

En opinión de los ministros señores Muñoz y Aránguiz, y el abogado integrante señor Gómez, el artículo 76 del Decreto Ley No 1.094, de 1975, es un precepto legal que, en cuanto a su aplicación al caso en concreto, pretende desconocer el derecho a contraer matrimonio de una persona extranjera que habita en Chile, ya que indirectamente y por vía interpretativa, según la autoridad administrativa, impide el ejercicio del derecho a contraer matrimonio de una persona extranjera por carecer de residencia legal en Chile.

El Servicio de Registro Civil e Identificación, como recurrido, informó a la Corte de Apelaciones de Santiago que su actuación se realizó conforme a la normativa del artículo 76 del Decreto Ley No 1.094, de 1975, que dispone: 
"Los servicios y organismos del Estado o Municipalidades deberán exigir a los extranjeros que tramiten ante ellos asuntos de la competencia de esos servicios, que previamente comprueben su residencia legal en el país y que estén autorizados o habilitados para realizar el correspondiente acto o contrato".

Por la vía administrativa, el servicio recurrido interpretó el art. 76 del mencionado Decreto Ley No 1.094, en cuanto a la imposibilidad de gestionar trámite alguno en dicho servicio, los que incluyen la celebración de matrimonios, sin que previamente se compruebe la residencia legal en el país de un extranjero.

En primera instancia, la Corte de Apelaciones de Santiago acogió el recurso de protección, considerando que la norma legal no está vigente actualmente, dada la entrada en vigencia de una norma posterior, cual es la Constitución Política de la República, en que, esta primera, se contrapone a lo dispuesto por la Carta Magna en el catastro de derechos fundamentales, en particular, la igualdad ante la ley. En sentido similar, el voto mayoritario de la Corte Suprema, que confirmó el fallo apelado ${ }^{4}$.

\section{La interpretación ADMinistrativa del artículo 76 del DeCreto Ley No 1.094 , DE 1975 , y SUS CONSECUENCIAS JURÍDICAS}

De la lectura de la normativa anteriormente señalada podemos desprender que el art. 76 regula dos aspectos diferentes. Uno es la comprobación de si los extranjeros están autorizados o habilitados para realizar el correspondiente acto o contrato ante determinado organismo del Estado. Un segundo aspecto es la exigencia de la documentación que compruebe la residencia legal del país de los extranjeros. Conforme al primer aspecto, es preciso señalar que no existe normativa alguna que limite a extranjeros para la celebración de un contrato de matrimonio; la habilitación para concurrir a su celebración está dada por los requisitos señalados en la Ley de Matrimonio Civil, no siendo requisitos discrecionales del Servicio de Registro Civil e Identificación. Conforme al segundo aspecto es que cualquier ente estatal debe requerir del extranjero que tramite ante él, conforme a algún asunto de su competencia, la comprobación de su residencia legal; cabe señalar que no es un requisito habilitante o un desglose que según su situación migratoria o residencia en Chile prestará o no el servicio respectivo que la ley ha investido al organismo en cuestión; que, a este respecto, todo ente estatal está

4 Corte Suprema, sentencia de 18 de abril de 2018, rol No 6111-2018. 
obligado, salvo normativa legal expresa, a prestar el servicio que en conformidad a la ley le ha sido brindado en el ámbito de sus atribuciones; en este caso, no se autoriza la falta de servicio.

No existe un vínculo jurídico razonable que fundamente la denegación de la celebración de un matrimonio civil y la situación migratoria de una persona extranjera. Al respecto, no existe un bien jurídico de relevancia nacional que sea visto afecto, sea la seguridad nacional, el orden público, la seguridad pública, la moral o las buenas costumbres; estos son algunos de los parámetros (art. 15, D.L. No $1.094,1975)$ que permiten orientar a la Administración para la concesión o denegación de la regularización de la situación migratoria de los extranjeros en Chile, en ausencia de criterios legales que permitan orientar la ponderación en la determinación y aplicación de estas medidas. Así también lo refuerza el "Reglamento de Extranjería" o Decreto No 597, de 1984, concediendo dichas atribuciones administrativamente resolutorias, que deben ser ejercidas discrecionalmente, con especial énfasis en la "conveniencia o utilidad" que reporte al país la concesión de dichos permisos". Dicha discrecionalidad, en el caso, cae en una hermenéutica casuística, que debe ser tratada delicadamente por parte de la Administración y con especial cuidado en la protección de los derechos humanos, en particular de la igualdad ante la ley de todos los habitantes de la República. En el caso, la interpretación discrecional de la administración a conceder la celebración de un matrimonio se ha transformado en una discriminación arbitraria.

En este punto, conectamos con los atributos de la personalidad, con especial énfasis en la capacidad que tienen todas las personas para celebrar actos jurídicos, en particular la capacidad de ejercicio. El Código Civil en su artículo 1447 señala quienes son incapaces para concurrir a la celebración de un acto jurídico, entre los cuales, cabe destacar, no se menciona a los "extranjeros", ni tampoco a aquellos "extranjeros indocumentados, irregulares, ilegales o sin residencia legal en Chile", si la capacidad está reconocida por la ley a todas las personas, en la interpretación administrativa de la normativa dispuesta en el artículo 76 del Decreto Ley No 1.094 de 1975 tendiente a la negación de la celebración de un contrato de matrimonio en cuanto uno de los intervinientes sea un extranjero sin residencia legal en Chile, lo que está realizando el Registro Civil es desconocer el atributo de la personalidad según la capacidad para celebrar actos o contratos por parte de

\footnotetext{
5 Así, el Tribunal Constitucional en sentencia de fecha 4 de julio de 2013, rol № 2273-2012, ha afirmado que la "utilidad" debe ser considerada en consideración al individuo y no del Estado, por cuanto los fines del ejercicio de dicha función se enmarcan en el desarrollo de la persona humana.
} 
los extranjeros sin residencia legal y, en consecuencia, negando la calidad jurídica de persona de estas, en el entendido de que los atributos de la personalidad los detentan todas las personas por el solo hecho de ser tales. En el mismo sentido, el Código Civil señala en su artículo 57 el llamado principio de igualdad entre nacionales y extranjeros, al no señalar diferencias entre chilenos y extranjeros, reconocido por la Constitución dentro del catastro de derechos fundamentales, según la igualdad ante la ley. En la praxis, señala Astudillo ${ }^{6}$, que la figura legal del extranjero sin residencia legal en Chile está en una situación vulnerable; están más expuestos a la conculcación de sus derechos. Además, reconoce que son mal llamados inmigrantes "ilegales" o "irregulares" (porque no existen personas regulares o irregulares, ni menos legales o ilegales).

El contrato de matrimonio es un contrato privado, en que el Estado juega el rol de interviniente en cuanto a su celebración. Dicho contrato solo importa a las partes, sin perjuicio de estar latamente regulado en la Ley de Matrimonio Civil; teniendo en cuenta, el Estado, a través del Servicio de Registro Civil e Identificación, la situación migratoria de un extranjero, como requisito habilitante o imperativo legal a fin de determinar la concesión o denegación para la celebración de un matrimonio ante él, siendo, en consecuencia, el punto decisorio a fin de considerar si presta el servicio a que está legalmente obligado, está condicionando a un extranjero a un estatus jurídico incluso mayor que aquel exigido, para tal efecto, a los nacionales, cuestión que vulnera gravemente el ejercicio de la garantía de la igualdad ante la ley.

\section{La CALIDAD JURÍDICA DE PERSONA DEL EXTRANJERO EN}

\section{SITUACIÓN MIGRATORIA IRREGULAR}

La distinción que realizó el Servicio de Registro Civil niega la calidad jurídica de persona de la que goza también el extranjero sin residencia legal en Chile o en situación migratoria irregular. Este se hace persona, biológicamente, a través de un hecho jurídico, al nacer de otro ser humano, con las consecuencias jurídicas que ello trae aparejado. La regla general es que toda persona sea legalmente capaz salvo aquellas que la ley declara incapaces; en general, aquellos señalados en el artículo 1446 del Código Civil. En particular, para celebrar un contrato de matrimonio se requiere cumplir con ciertos requisitos de existencia y validez que, como respecto de cualquier otro acto jurídico, a falta de una ordenación sistemática legal del

6 Astudillo (2014), p. 61. 
acto jurídico, la doctrina ha realizado una de manera detallada y rigurosa. Así, la doctrina ha distinguido aquellos elementos comunes aplicables a todos los actos jurídicos, conceptualizados como la manifestación de voluntad que se dirige a un fin práctico tutelado por el ordenamiento jurídico ${ }^{7}$, requisitos que le otorgan la fisonomía propia a cada uno de aquellos actos y contratos, denominados requisitos de existencia y de validez. Los primeros requisitos son aquellos indispensables para que el acto jurídico exista como tal y produzca sus efectos. Si faltan, el acto es jurídicamente inexistente, por lo que no produce efecto alguno; entre ellos, se cuentan la voluntad, objeto, causa y solemnidades: Los requisitos de validez son aquellos necesarios para que el acto tenga una vida sana y produzca sus efectos en forma estable; así: voluntad no viciada, objeto lícito, causa lícita, capacidad.

Que el extranjero en situación migratoria irregular, al ser persona, ya que nació biológicamente de otro ser humano, es titular de derechos y obligaciones, noción de derecho subjetivo que supone un poder conferido a una persona sobre algo que es distinto a ella, algo atribuible a ella ${ }^{8}$.

"Que lo primero que cabe señalar es que el Código Civil señala que la existencia legal de toda persona principia al nacer (artículo 74). Y termina con la muerte natural (artículo 78). El nacimiento, agrega, se produce al separarse completamente de la madre (artículo 74). Asimismo, el Código define como persona a 'todos los individuos de la especie humana' (artículo 55). Finalmente, como la existencia legal principia al nacer, ello en el Código Civil produce dos efectos. Por una parte, los derechos entregados al que está por nacer, quedan diferidos hasta que nazca. Si nace entra en su goce (artículo 77). Por la otra, si no nace, se reputa que no ha existido jamás (artículo 74). Ello ocurre tanto si muere en el vientre materno como si perece antes de estar completamente separado de su madre o si no sobrevive a la separación un momento siquiera (artículo 74)" 9 .

Constitucionalmente, uno de los efectos más importantes al atribuir a alguien la calidad jurídica de persona es que solo estas tienen derechos ${ }^{10}$. De esta forma lo reconoce la Constitución al señalar que los derechos se aseguran a todas las personas.

Así, las personas, a partir del nacimiento, adquieren originaria y gratuitamente esa calidad, biológica y jurídica; esta se tiene para siempre, no se suspende ni se

7 Vial del Río (2006), pp. 36-37.

8 Domínguez (2011) p. 645.

9 Tribunal Constitucional, rol No 3729-2017, de 28 de agosto de 2017.

10 Tribunal Constitucional, rol No 3729-2017, de 28 de agosto de 2017. 
priva, ni se cancela, y tampoco es renunciable; esta es inherente. Las personas la tienen por igual, cualquiera sea "su orientación sexual o su identidad de género, los niños, los jóvenes, los adultos, los creyentes y no creyentes, los casados y los solteros, los que pertenezcan o no a etnias originarias, los que tengan alguna enfermedad o alguna discapacidad" 11 y, para lo atingente, los chilenos y extranjeros. Al tenerla, es oponible a todos.

En síntesis, el nacer de otro ser humano, el legislador reconoce y hace atribuible a un hecho biológico la adquisición de la calidad jurídica de persona.

La Constitución usa el término "persona" en un sentido amplio, sin distinción, como lo aclaró el Tribunal Constitucional en la sentencia de fecha 28 de agosto de 2017. Esta es una titularidad genérica: "no solo no discrimina contra los extranjeros sino que les reconoce tal titulo de derechos plenamente"12.

La persona posee atributos de la personalidad, dentro de los cuales está la capacidad que es, a su vez, un requisito de existencia común a todo acto jurídico, y se define como la aptitud para obligarse jurídicamente. La capacidad es la aptitud legal de las personas para adquirir y ejercitar por sí los derechos civiles. Para adquirir derechos, se la denomina capacidad de goce, y la tienen todas las personas por el hecho de ser tales, siendo uno de los atributos de la personalidad. La capacidad de ejercicio es la aptitud para ejercitar, para hacer valer los derechos.

\section{LA PROTECCIÓN Y FORTALECIMIENTO DE LA FAMILIA, SIENDO EL MATRIMONIO SU BASE PRINCIPAL}

La sentencia en comento, pronunciada por la Corte Suprema, se desarrolla sobre la base de que la Constitución Política de la República posee eficacia directa con efectos derogatorios de los preceptos preconstitucionales, por lo que, de existir un conflicto de esa naturaleza, considera que es de competencia de los tribunales ordinarios examinar la pérdida de vigencia. La fuerza normativa de la Constitución en el caso concreto se constató al afirmar el tribunal que "las normas constitucionales y la convención internacional disponen que toda persona que habita el Estado de Chile es titular del derecho a contraer matrimonio y fundar una familia, en lo cual la autoridad tiene el deber de ampararla, por lo mismo, no

11 Tribunal Constitucional, rol No 3729-2017, de 28 de agosto de 2017.

12 Tribunal Constitucional, rol No 2273-2012, de 4 de julio de 2013. 
puede ser turbado en el ejercicio de ese derecho"13. Es sugerente el razonamiento de la corte sobre el derecho de los recurrentes a contraer matrimonio, regulado en la Convención Americana de Derechos, la cual no puede ser limitada por exigencias formales previas y es reconocido a todo habitante de la República, así como lo es todo derecho esencial que emana de la naturaleza humana, de aquellos regulados en el artículo 19 de la Constitución Política de la República, como también los establecidos en tratados internacionales que versen sobre derechos humanos y que se encuentren ratificados y vigentes en el ordenamiento jurídico nacional. Sin embargo, en este punto, la Corte Suprema pudo haber argumentado que el derecho a contraer matrimonio es una extensión del derecho a la vida privada, que al amparar a la persona natural y su familia, incluye al matrimonio, al ser este "la base principal de la familia", cuya protección reconoce de manera expresa el art. 20 de la Constitución.

Se reconoce al Sistema Interamericano de Derechos Humanos como uno de los principios fundantes y estructurantes del derecho internacional de los derechos humanos ${ }^{14}$, que, en consecuencia, es una fuente del ordenamiento jurídico internacional, en cuanto a esta materia.

En este mismo sentido, la Convención Interamericana de Derechos Humanos asegura a todas las personas el derecho a contraer matrimonio, que, como se señaló con anterioridad, emana de la naturaleza humana. Así, también en la Declaración Universal de los Derechos Humanos, en su artículo 16. 1, se reconoce a "los hombres y las mujeres, a partir de la edad núbil, tienen derecho, sin restricción alguna por motivos de raza, nacionalidad o religión, a casarse y fundar una familia, y disfrutarán de iguales derechos en cuanto, al matrimonio, durante el matrimonio y en caso de disolución de matrimonio". En su correlativo prescribe "sólo mediante libre y pleno consentimiento de los futuros esposos podrá contraerse el matrimonio". En el mismo sentido, reconoce el artículo $2^{\circ}$ de la Ley de Matrimonio Civil el derecho al matrimonio o jus connubii, al señalar que "La facultad de contraer matrimonio es un derecho esencial inherente a la persona humana, si se tiene edad para ello".

El inciso segundo del artículo $1^{\circ}$ de la Ley de Matrimonio Civil, Ley No 19.947 de 2004, señala que "el matrimonio es la base principal de la familia", indicando que el matrimonio es la forma principal de constituir una familia; a contrario sen$s u$, reconoce el legislador que hay otras formas de constituir una familia, las que,

13 Corte Suprema, rol No 6111-2018, de 18 de abril de 2018.

14 Gros (1984), p. 227. 
en todo caso, deben tener protección y fortalecimiento por parte del Estado, en cualquiera de sus formas, según lo dispuesto en el artículo $1^{\circ}$ de la Constitución Política de la República, que establece que la familia es el núcleo fundamental de la sociedad, siendo deber del Estado dar protección a la población y a la familia, así como propender al fortalecimiento de esta ${ }^{15}$.

Se ha reconocido por nuestros tribunales superiores de justicia que, "el concepto de "familia" debe recibir siempre una interpretación amplia, porque sólo de esa manera pueden asegurarse efectivamente los derechos fundamentales. Así dicha expresión no alude únicamente a la existencia de un matrimonio, ni siquiera de la cohabitación. Comprende, en general, las relaciones entre dos personas, entre padres e hijos, con exigencias mínimas de lazos de vida, vinculaciones de dependencia económica, relación directa y regular, etcétera"16. De esta forma, no cabe discriminar entre la familia que ha surgido como consecuencia de un matrimonio y otra constituida sobre la base de la convivencia como una situación de hecho.

En este sentido, Jorge del Picó señala que "la defensa de la familia es una consecuencia del interés público en su protección jurídica, originada en su apreciación como institución social y que se manifiesta, entre otras facetas de tutela, en la indisponibilidad de las normas del Derecho matrimonial como parte integrante del Derecho de Familia" ${ }^{17}$. En este orden de ideas, se reconoce el derecho a contraer matrimonio como un antecedente constituyente de la base fundamental de la familia, en que el Estado debe tratar a todos los individuos con igual respeto y consideración.

El sistema chileno civil, al igual que los otros de tradición continental, es un sistema codificado. Como tal, se basa en una estructura sistemática, donde ciertos principios estructuran las soluciones particulares y solo en la medida en que hay concordancia entre dichos valores y las normas y sus interpretaciones el sistema se legitima. De ahí la importancia y centralidad que tiene el principio de igualdad en tanto valor estructurante del sistema civil ${ }^{18}$.

La igualdad y no discriminación están íntimamente ligadas y se llega a plantear la figura de que ambas constituirían una suerte de "dos caras de una misma moneda"19. Sin perjuicio de que es posible establecer ciertas limitantes legítimas

15 Corte Suprema, rol No 3793-2006, de 28 de agosto de 2006.

16 Corte de Apelaciones de Santiago, rol No 19-2013, de 21 de enero de 2013.

17 Del Picó (2010), pp. 119-120.

18 NASH Y NúÑEZ (2014), p. 51.

19 Corte Interamericana de Derechos Humanos, Opinión Consultiva OC-4/84, de 19 de enero de 1984. 
al principio de igualdad, estas deben recaer en una causa razonable que, en caso del ejercicio de la función pública y la prestación de servicios por parte de entes de naturaleza estatal, responden a un mandato legal o al resguardo de un bien jurídico de relevancia nacional. Si bien la igualdad jurídica en el ámbito de derecho de familia reconoce la existencia de instituciones y normas que afectan dicho principio en cuanto a la jerarquización de las relaciones, estereotipos de género y de distinciones, exclusiones y preferencias que, en cuanto a una interpretación ligada a la realidad social imperante, no siempre encuentra un cobijo en una justificación objetiva y razonable, pero en cuanto a la adquisición de dichos derechos, en particular respecto a contraer matrimonio, la distinción solo obedece a criterios estrictamente normativos que obedecen a criterios objetivos (diferencia de sexo entre los contrayentes, mayoría de edad, por regla general) y subjetivos (capacidad para contraer matrimonio) que, en ningún caso deben ser condicionados a la nacionalidad de los esposos. Así, el legislador sí atiende a otros como lo son la edad, el sexo y la condición de los mismos.

Una prohibición o limitante relativa al ejercicio de un derecho humano debe contar con una regulación normativa expresa. No encontrando limitante teórico-jurídica, en el caso en concreto, en cuanto al ejercicio del derecho a contraer matrimonio, el cual ha de ser respetado y ejercido sin limitantes formales previas, como ocurre en el caso en comento según se requiere por el Servicio de Registro Civil e Identificación la exhibición de una cédula de identidad, por parte del extranjero, que acredite su residencia legal en el país so pena de no llevar a cabo la celebración del contrato de matrimonio. Así, el Estado debe propender a garantizar que todos los habitantes de la República, chilenos y extranjeros (cualquiera sea su situación migratoria), puedan ejercer razonablemente y dentro de un marco jurídico, aquellos derechos que emanan de su naturaleza humana, ya que estos no admiten distinción en cuanto a su adquisición, ejercicio o pérdida; son iguales para todas las personas, quienes los adquieren a través de un hecho que jurídicamente tiene un reconocimiento, cual es el nacimiento. De esta forma, un extranjero debe tener igual trato respecto de los nacionales ante cualquiera; su condición humana y las consecuencias que de ella derivan son oponibles erga omnes.

El artículo $3^{\circ}$ de la Ley de Matrimonio Civil, Ley No 19.947 de 2004, reconoce el principio de intervención judicial a favor del matrimonio, en cuanto a la posibilidad de recurrir ante un juez de la República dado un conflicto jurídico derivado de la unión matrimonial "cuando ésta se vea amenazada, dificultada o quebrantada". Si bien esto lo reconoce el legislador a dicha relación "válidamente 
contraida", debe entenderse en todo el iter contractual que, en la materia que nos convoca, a propósito de la inmigración, a la luz de la experiencia conocida en Europa en aquellas situaciones en que las autoridades administrativas han expulsado a un extranjero que, en el período previo al acto que le afecta, ha contraído matrimonio con una ciudadana del país que dicta la resolución, sea previo o posterior.

Como se mencionó con anterioridad, el derecho a contraer matrimonio está reconocido en un instrumento internacional, cual es la Convención Americana sobre Derechos Humanos o el Pacto San José de Costa Rica, y también lo parece estar a nivel interno, en el artículo $2^{\circ}$ de la Ley de Matrimonio Civil, Ley No 19.947 de 2004, en vinculación con el actuar que debe mantener el Estado en ejercicio de su potestad administrativa cuando concurran ante sus servicios extranjeros, cualquiera sea la calidad jurídica por la que los requieran, ya que no es un parámetro determinante a fin de considerar, en general, la concesión o no de la prestación del servicio a que están obligados, como órganos de la Administración. El Tribunal Constitucional ${ }^{20}$ afirmó que "no es admisible para el Derecho Internacional de los Derechos Humanos, concebir la potestad administrativa de admisión del extranjero a cada país, únicamente desde la óptica del orden público interno y como medida de policía de seguridad". Pues se debe tener en consideración, la normativa legal extranjera debidamente ratificada y actualmente vigente, así como aquella nacional, en concordancia con aquellos derechos que emanan de la naturaleza humana.

Existe un problema jurídico de gran relevancia que afecta al ejercicio de los derechos de la población inmigrante, al tratar de ejercerlos en el territorio nacional, en cuanto al trato institucional de la Administración, puesto que la juridicidad del extranjero (cualquiera sea su situación migratoria), en la práctica, está desembocando en una serie de problemas y dificultades que deben ser abordados en forma sistemática, tanto a nivel legal como reglamentario, particularmente en lo relativo a la garantía de la igualdad del ejercicio de los derechos.

El dictamen emanado de la Contraloría General de la República No 19.811, de fecha 7 de agosto de 2018, en que el Servicio de Registro Civil e Identificación solicita a dicha Contraloría General un pronunciamiento que determine si se ajusta a derecho que los oficiales civiles de ese servicio autoricen la celebración de matrimonios o acuerdos de unión civil en que uno de los interesados o ambos

20 Tribunal Constitucional, rol No 2273-2012, de 4 de julio de 2013. 
sean extranjeros y carezcan de residencia legal en Chile, confirma el razonamiento de la Excelentísima Corte Suprema en los fallos anteriormente citados ${ }^{21}$, además del fallo ${ }^{22}$ en comento, toda vez que dicho tribunal ordenó a ese servicio celebrar un matrimonio en el que uno de los contrayentes era extranjero y no acreditaba su residencia legal en el país.

La Contraloría General de la República, luego de promocionar y recordar la protección que el Estado le debe a la familia y su constitución legal a través del matrimonio, así como también que el legislador contempla la facultad de contraer matrimonio y celebrar acuerdos de unión civil como derecho de todas las personas que cumplen con los requisitos que esos cuerpos legales establecen y que preceden en este comentario de jurisprudencia, los oficiales del Servicio de Registro Civil e Identificación se encuentran en la obligación de proceder a la celebración de los respectivos contratos, cuando se satisfagan dichos supuestos.

En cuanto al artículo 76 del Decreto Ley No 1.094, de 1975, señala dicho dictamen que el ejercicio de esta labor de los servicios y organismos del Estado o municipalidades, no puede pretender la limitación a los derechos a contraer matrimonio o adoptar un acuerdo de unión civil. Estos deben prestar el servicio que por ley les ha sido investido, sin establecer al respecto condiciones de ningún tipo ni requisitos de extranjería.

A nivel nacional, aún es importante la construcción de herramientas teóricas que, desde la dogmática jurídica chilena, permitan generar un nuevo paradigma normativo para enfrentar con éxito los desafíos del escenario migratorio actual que satisfagan los estándares fijados en el derecho internacional.

\section{Bibliografía CITADA}

Astudillo Contreras, Omar (2014): "El estatus jurídico de los inmigrantes indocumentados: Un nuevo reto para el derecho del trabajo", en Revista de Derecho Laboral y Seguridad Social, Volumen II (No 1), pp. 61-78.

Del Picó Rubio, Jorge (2010). Derecho matrimonial chileno. (Santiago, Abeledo Perrot-LegalPublishing).

Domínguez Hidalgo, Carmen (2011): "Los derechos de la personalidad y el principio de reparación general del daño", en Estudios de Derecho Civil, Volumen 4.

21 Corte Suprema, rol No 35236 y No 12.130, de fecha 30 de agosto de 2016 y 12 de julio de 2018, respectivamente.

22 Corte Suprema, rol No 6111-2018, de 18 de abril de 2018. 
Gros EsPiELl, Héctor (1984): "Los derechos humanos y el sistema interamericano", en Vasak: Las dimensiones internacionales de los derechos humanos, Volumen III.

Nash Rojas, Claudio, y NúNEzz Donald, Constanza (2014): "Ley de Matrimonio Civil y derechos humanos: Una década después", en Revista de Derecho de Familia, Volumen III (№ 3).

Vial del Río, Víctor (2006): Teoría general del acto jurídico. $5^{\circ}$ edición (Santiago, Editorial Jurídica de Chile).

\section{JURISPRUDENCIA CITADA}

Jessica Toro y otro con Servicio de Registro Civil e Identificación (2018), Corte Suprema, 12 de julio de 2018 (acción de protección por matrimonio).

Leila Tirado Guevara contra el Ministerio del Interior (2006), Corte Suprema, 7 de agosto de 2006 (acción de amparo).

Mondragón con Servicio de Registro Civil (2018,) Corte Suprema, 18 de abril de 2018 (acción de protección por matrimonio).

Morales García Sandra Milena con Departamento de Extranjería y Migración (2013), Corte de Apelaciones de Santiago, 21 de enero de 2013 (acción de amparo). Propuesta de Modificación a la Constitución Politica de Costa Rica Relacionada con la Naturalización (1984), Corte Interamericana de Derechos Humanos, 19 de enero de 1984 (opinión consultiva).

Requerimiento de inaplicabilidad por inconstitucionalidad presentado por el ciudadano haitiano Daniel Alerte, respecto de los artículos 13, 64 No 2 y 67 del Decreto Ley $N^{o} 1.094$, de 1975, que establece normas sobre extranjeros en Chile, en relación a los autos sobre recurso de protección, de que conoce la Corte de Apelaciones de Santiago, bajo el rol No 21751-2012 (2013), Tribunal Constitucional, 4 de julio de 2013 (requerimiento de inaplicabilidad por inconstitucionalidad).

Requerimiento de inconstitucionalidad presentado por un grupo de Senadores, que representan más de la cuarta parte de los miembros en ejercicio, respecto del proyecto de ley que regula la despenalización de la interrupción voluntaria del embarazo en tres causales correspondientes al Boletín No 9.895-11 (2017), Tribunal Constitucional, 28 de agosto de 2017 (requerimiento de inconstitucionalidad).

Verónica Venegas Cáceres y otro con Servicio de Registro Civil e Identificación (2016), Corte Suprema, 30 de agosto de 2016 (acción de protección por matrimonio). 
